\title{
EL DOMINIO RÚSTICO DEL MONASTERIO DE SAN MILLÁN DE LA COGOLLA EN EL SIGLO DE SU CLAUSURA (1752-1841)
}

\section{Santiago Ibáñez Rodríguez ${ }^{*}$}

San Millán de la Cogolla ha sido, y es ahora, el monasterio riojano más afamado. $Y$ es posible que acumulara, y aún acumule, motivos suficientes para serlo. Se le asocia con la expansión territorial del Reino de Navarra hacia el sur, y con la consolidación del Condado de Castilla frente al Reino de León primero, y al de Navarra más tarde'. Se ha destacado la importancia de su escriptorio medieval, que conocemos detalladamente después de la publicación del libro de Manuel Díaz ${ }^{2}$. Y sobre todo, se le une en nuestros días, en un discurso entre lingüístico y político, al origen de la lengua castellana. En un principio se encontraron los primeros vagidos -la palabra no es nuestra sino de los especialistas de estos temas- de esta lengua en el códice AEmilianensis 60 (las venerables Glosas reivindicadas por los políticos riojanos y los Amigos de La Rioja), y ahora situado en el Manuscrito 46 del año $964^{3}$. Pero estos méritos, obviamente, debieron soportarse en un algo. Angel García de Cortázar ${ }^{4}$ demostraba hace años que el dominio económico emilianense jugó un papel muy destacado en todo ello. Nosotros pretendemos en este trabajo analizar algunos de esos aspectos materiales de San Millán de la Cogolla, pero refiriéndonos al último siglo de su exis-

*. Doctor en Historia. Dpto. de Ciencias Humanas y Sociales, Universidad de La Rioja. Mi especial agradecimiento a Francisco Bermejo Martín, a quien todo debo.

1. Cfr. PÉREZ DE URBEL, J. Navarra y Castilla en el siglo X. Príncipe de Viana V (1944), p. 373. UBIETO, A. Las fronteras de Navarra. Principe de Viana XIV (1953), P. 65.

2. DÍAZ, M. Libros y librerías en La Rioja altomedieval. Logroño 1979.

3. GARCÍA TURZA, C. y J. En los orígenes de la lengua y cultura españolas: el manuscrito 46 de la Real Academia de la Historia. Manuscrito 45. La Rioja, Domingo en Portada, 8 de junio de 1997, pp. VI-XII.

4. GARCÍA DE CORTÁZAR, A. El dominio del monasterio de San Millán de la Cogolla. Salamanca 1969. 
tencia, a saber, desde mediados del siglo XVIII, concretamente desde 1752, fec ha de la confección del Catastro del Marqués de la Ensenada, hasta el 8 de marzo de 1836, cuando los liberales españoles decretaron la exclaustración total de las instituciones religiosas de regulares, y con ellas, la de nuestro monasterio ${ }^{5}$.

Antes de dedicarnos enteramente al análisis de las posesiones o tenencias económicas del monasterio de San Millán, situémosle en su contexto. La Dirección del Ramo de Monasterios y Conventos Suprimidos, en un documento elaborado a lo largo del año 1841 bajo el título, Clero regular. Estados de fincas rústicas y urbanas que pertenecieron a monasterios y conventos suprimidos. Logroño $1841^{6}$, declara que el número de establecimientos del estado eclesiástico con posesiones rústicas y urbanas en la entonces denominada provincia de Logroño ascendían a cuarenta y dos. Estas instituciones estaban domiciliadas en dieciocho enclaves diferentes de la provincia (villas y parajes aislados) y, el resto, en cinco lugares foráneos. Lo podemos comprobar en Cuadro 1.

Cuadro 1. Establecimiento del clero regular en La Rioja en 1836.

Clasificados por instituciones, órdenes y lugar de residencia

\begin{tabular}{ll}
\hline Orden religiosa & Avecindada en \\
\hline Agustinas & Logroño \\
& Ágreda (So) \\
Agustinos & Haro \\
Benitos & San Millán de la Cogolla \\
& Santa María la Real, Nájera \\
& Valvanera (Anguiano) \\
& El Espino (Valladolid) \\
& Obarenes (B) \\
& Cañas \\
Bernardas & Herce \\
& Santo Domingo de la Calzada \\
& San Prudencio \\
Bernardos & Bugedo (B) \\
& Herrera (B) \\
& Logroño \\
Carmelitas descalzas & Calahorra \\
& Calahorra \\
Carmelitas descalzos & Logroño \\
& La Esperanza de Alfaro
\end{tabular}

5. Para el proceso general de exclaustración puede consultarse REVUELTA GONZÁLEZ, $M$. La Exclaustración (1833-1840). BAC 1976, siempre que se expurguen algunas de sus interpretaciones.

6. HN, Hacienda, Leg. 4542 b. 


$\begin{array}{ll} & \text { Casalarreina } \\ \text { Dominicos } & \text { Logroño } \\ & \text { Vitoria } \\ & \text { Entrena } \\ & \text { Santa Elena, Nájera } \\ & \text { Madre de Dios, Logroño } \\ & \text { La Concepción, Alfaro } \\ & \text { Santa Clara, Arnedo } \\ & \text { Alfaro } \\ \text { Franciscanos } & \text { Vico, Arnedo } \\ & \text { Calahorra } \\ & \text { Cornago } \\ & \text { Logroño } \\ & \text { Nájera } \\ & \text { Nalda } \\ & \text { Navarrete } \\ & \text { Santo Domingo de la Calzada } \\ & \text { Torrecilla de Cameros } \\ & \text { La Estrella, San Asensio } \\ \text { Jerónimos } & \text { San Miguel del Monte, Miranda (B) } \\ \text { Mercedarios calzados } & \text { Logroño } \\ \text { Trinitarios calzados } & \text { Alfaro } \\ & \text { Logroño } \\ & \end{array}$

Nuestro trabajo pretende fundamentalmente alcanzar dos objetivos. El primero, concretar la dimensión y la estructura del dominio rústico del monasterio de San Millán en dos fechas separadas por un siglo, 1752 y 1841 . El segundo, comparar los resultados obtenidos para uno y otro año y establecer las líneas maestras de su interpretación. En resumen, llevar a cabo lo que se conoce como análisis sincrónico y dicrónico de un hecho histórico con la particularidad de encuadrarlo cronológicamente en la llamada crisis del Antiguo Régimen?.

El arco cronológico de estudio viene condicionado por las fuentes. El año de 1752 corresponde con la realización en Castilla de la encuesta para establecer una Unica Contribución, o más vulgarmente conocida como el Catastro de Ensenada ${ }^{8}$ Y el de 1841, coincide con la finalización en nuestra provincia

7. El número de trabajos sobre el dominio del monasterio de San Millán durante la Edad Moderna son realmente escasos, se podrían apuntar varios, pero quizá uno de los mejor planteados, sin que tuviese continuidad, fue MORATÉ J., Le domaine de San Millán de la Cogolla, Mémoire de D.E.A. de la Université de Toulouse-Le Mirail, U.F.R. d'Histoire, Histoire de l'Arte et Archéologie, 1991.

8. La bibliografía sobre los Catastro en España y su entorno europeo es amplísima. Juan Pro Ruiz aporta una de 346 títulos para el siglo XIX y sus antecedentes en PRO RUIZ, J. Materiales 
de un Inventario realizado por los funcionarios del gobierno sobre las fincas rústicas y urbanas que pertenecieron a los monasterios y conventos suprimidos que está depositado en el Archivo Histórico Nacional, como ya hemos mencionado. Los datos de 1752 están tomados del Libro mayor de raíz de eclesiásticos del Catastro de Ensenada de las diferentes poblaciones; el Libro ha sido trabajado siguiendo estos criterios: primero, hemos buscado el encabezamiento de Monasterio -y otras denominaciones que también se dan- de San Millán de la Cogolla en el índice alfabético inicial del libro raíz de cada pueblo; segundo, hemos anotado de los diferentes pueblos con posesiones de San Millán los apuntes siguientes: el tipo de propiedad de la parcela (heredad, tierra, viña, huerta, prado,...), la superficie de la misma en su medida original (comúnmente fanega para la sembradura y obrada para la viña), la calidad (su calificación distinguiendo secano y regadío) y los nombres de los términos municipales (los pagos); tercero, hemos globalizado los datos por superficie de todas las parcelas por cada tipo de propiedad en cada localidad; y cuarto, finalmente, hemos elaborado un cuadro resumen, pueblo por pueblo, del todo el dominio de San Millán en La Rioja. La elaboración del documento de 1841, aunque laboriosa, ha resultado mucho más fácil. Hemos agrupado por poblaciones con dominios del Monasterio los mismos datos recogidos en el Catastro. No obstante, al operar sobre la fuente, nos hemos encontrado con errores cuantitativos, y con sumas generales del número de parcelas y de extensiones superficiales que no cuadran, en general, con problemas metrológicos.

No quisiéramos eludir un problema tan importante como el de las transformaciones de los predios de los monasterios en el tránsito del siglo XVIII al XIX ${ }^{9}$ refugiándonos en problemas métricos, pero hemos de plantearlos y resolverlos adecuadamente para que nuestras conclusiones sean útiles. En efecto, el mayor inconveniente que resulta de la confrontación de las dos fuentes analizadas ha sido la unificación métrica. El tema no es nuevo, la diversidad de medidas es consubstancial al Antiguo Régimen ${ }^{10}$ y su empleo, que no estaba exento de simbolismo", aún fue más complejo a partir de la segunda mitad del XVIII cuando

para el estudio de la cuestión catastral en España. El siglo XIX. Agricultura y Sociedad 44 (1987), pp. 325-377. Para la visión general del Catastro de Ensenada se puede consultar el breve trabajo de CALVO ALONSO, C. El Catastro de la Ensenada. Proyecto de Unica Contribución en la Corona de Castilla. SEGURA I MAS, A. El Catastro en España (1714-1906), vol. I. Barcelona 1988, pp. 89-111. Ver una visión más completa en CAMARERO BULLÓN, C. Burgos y el Catastro de la Ensenada. Burgos 1989. También, El debate de la Unica Contribución: Catastrar las Castilla, 1749. Madrid 1993.

9. Ver ATIENZA LÓPEZ, A., Propiedad y señorío en Aragón. El clero regular entre la expansión y la crisis, 1700-1835, Zaragoza 1993.

10. VID, GUTIÉRREZ BRINGAS, M.A. La metrología: un problema para la historia agraria (convertibilidad métrica y recopilación bibliográfica). Noticiario de Historia Agraria 12 (1996), pp. 221-248.

11. KULA, W. Problemas y métodos de la historia económica. Barcelona 1973. Y, Las medidas y los hombres. Madrid 1980. 
se buscó la fijación de la nomenclatura y la realidad métrica ${ }^{12}$. Analizaremos a continuación este problema en el caso práctico del monasterio de San Millán de manera que, a partir de ahora, organizaremos el artículo abarcando los siguientes temas. Concretaremos la dimensión del predio del monasterio tanto en 1752 y en 1841 una vez salvados los inconvenientes métricos; igualmente haremos las comparaciones oportunas entre una y otra fecha. A continuación estudiaremos la organización espacial del dominio rústico por los diferentes enclaves regionales y sus posibles variaciones temporales. Seguidamente hab laremos de la parcelación del terrazgo que controla el monasterio y si se puede establecer alguna tipología. Finalmente, describiremos los tipos de cultivo, su localización y sus proporciones por poblaciones y comarcas para intentar definir la imagen del paisaje agrario.

En los lugares donde el monasterio de San Millán de la Cogolla disponía de patrimonios rústicos la medida de la tierra de sembradura que aparece en el Catastro de Ensenada es la fanega, la medida de la viña es la obrada. Ahora bien, el número de varas que abarcaban las fanegas eran diferentes de un municipio a otro, las había de todos los tipos, desde 3.000 , la más usual, hasta la de 4.000 varas castellanas. Lo mismo ocurría con las obradas, las hay desde las 150 cepas hasta las 250, aparte de que en sí, la obrada no era una medida de superficie sino de trabajo. Pero esto no será un problema porque todo ello ya ha sido estudiado adecuadamente para el tiempo del Catastro de Ensenada en La Rioja ${ }^{13}$. Pasemos a observar lo que ocurre en la fuente de 1841. La medida de superficie de la sembradura es de nuevo la fanega pero ¿la fanega de cuántas varas castellanas?, ahora no disponemos de una documento tan preciso como el Catastro que en su interrogatorio incluía la respuesta a esta peculiaridad.

Alentados por una solución factible hemos sometido las cifras de 1841 a diferentes hipótesis. Hemos confrontado los datos de 1841 con los de 1752 en aquellas poblaciones donde el número de parcelas eran las mismas en una y otra fecha; el resultado ha sido inútil. En cuanto a la capacidad de la fanega, hemos probado a comparar aquellos ejemplos donde coincide la fanega de 3.000 varas, la más común en los lugares donde poseía tierras el monasterio de San Millán según el Catastro de Ensenada, y el Diccionario de Madoz ${ }^{14}$. En este caso parece darse la transformación, pero no siempre sucede así. Las diferencias entre unos y

12. GUTIÉRREZ CUADRADO, J. y PESET, J.L. Metro y kilo. El sistema métrico decimal en España, Madrid 1997.

13. IBÁÑEZ RODRÍGUEZ, S. La necesidad de medir. La metrología agraria del Antiguo Régimen en La Rioja, Brocar 19 (1995), pp. 133-164. La complejidad de medidas usadas también se pueden observar en otras regiones españolas SÁNCHEZ SALAZAR, F. Medidas de superficie tradicionales utilizadas en el Reino de Sevilla y su equivalencias con el sistema métrico decimal. GÓMEZ MENDOZA, A. (coord.), Economía y sociedad en la España Moderna y Contemporánea. Madrid 1996, pp. 55-69.

14. En el apartado de Monedas, pesos y medidas dedicado a la entrada de Provincia de Logroño se escribe: "generalmente la fanega tiene 3.000 varas cuadradas; pero en el partido 
otros ejemplos son en unas ocasiones de escasa consideración, pero en otros son lo suficientemente importantes como para que la prudencia invite a no tenerlas en consideración. Los problemas, además, son mayores si las parcelas comparadas corresponden a las ocupadas por el viñedo, en una y otra fecha se utilizan, claramente, dos medidas diferentes.

Cuadro 2. La explotación agrícola del monasterio de San Millán de la Cogolla

a) Según la suma de las diferentes medidas locales

\begin{tabular}{|c|c|c|c|c|c|c|}
\hline \multirow{2}{*}{$\frac{\text { Tipo de tierra }}{\text { Sembradura }}$} & \multicolumn{3}{|c|}{ Año 1572} & \multicolumn{3}{|c|}{ Año1841 } \\
\hline & \multicolumn{3}{|c|}{8.953 fanegas y 6 celemines } & \multicolumn{3}{|c|}{7.656 fanegas y 7 celemines } \\
\hline Huerta & \multicolumn{3}{|c|}{21 fanegas y 8 celemines } & \multicolumn{3}{|c|}{32 fanegas y 9 celemines } \\
\hline Prado & \multicolumn{3}{|c|}{254 fanegas y 8 celemines } & \multicolumn{3}{|c|}{24 fanegas y 3 celemines } \\
\hline Viña & \multicolumn{3}{|c|}{3.972 obradas } & \multicolumn{3}{|c|}{563 aranzadas y 350 estadiles } \\
\hline \multicolumn{7}{|c|}{ b) Convertido a hectáreas } \\
\hline \multirow[t]{2}{*}{ Tipo de tierra } & \multicolumn{2}{|c|}{ Año 1572} & \multicolumn{2}{|c|}{ Año1841 } & \multicolumn{2}{|c|}{ Incremento } \\
\hline & Has. & $\%$ & Has. & $\%$ & Has. & $\%$ \\
\hline Sembradura & 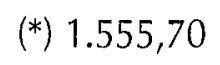 & 87,2 & $1.630,98$ & 88,0 & $+75,28$ & $+3,8$ \\
\hline Huerta & 3,77 & 0,2 & 7,68 & 0,4 & $+03,91$ & $+103,7$ \\
\hline Prado & 53,23 & 3,0 & 5,07 & 0,3 & $-48,16$ & $-90,5$ \\
\hline Viña & 171,54 & 9,6 & 208,58 & 11,3 & $+37,04$ & $+21,6$ \\
\hline Era & - & 0,0 & 0,08 & 0,0 & $+00,08$ & $+100,0$ \\
\hline TOTAL & $1.784,24$ & 100,0 & $1.852,39$ & 100,0 & $+68,15$ & $+3,8$ \\
\hline
\end{tabular}

(*) En la sembradura de 1752 no se contabilizan las 1.540 fanegas $(321,86$ Has.) de carrascal del priorato de Cihuri que, a todas luces, no es considerado en 1841

Finalmente, hemos optado por seguir la siguiente metodología para convertir todas las superficies a hectáreas. Los datos que proporciona el Catastro de Ensenada, tanto de fanegas de diferente superficie como de obradas, se han transformado municipio a municipio siguiendo escrupulosamente las recomendaciones del Catastro ${ }^{15}$. Para los datos del siglo XIX hemos considerado para la sembradura, huertas y prados la fanega de 3.000 varas $(0,209$ hectáreas), y para evaluar las aranzadas de la viña, y el escaso olivar, y una dehesa nos serviremos de la aranzada de 0,37 hectáreas. Justificamos las transformaciones para el

de Arnedo se diferencian las fanegas de regadío y de secano...". Edición facsímil para La Rioja, Logroño 1985, p. 121.

15. Al hilo de las conclusiones de IBÁÑEZ RODRÍGUEZ, S. La necesidad de medir... 
año de 1841 en cuanto a sembradura por ser la fanega más común de la zona de la provincia donde se localizan la mayoría de las posesiones del monasterio de San Millán de la Cogolla; y, en cuanto al viñedo, porque los resultados del Catastro de Ensenada, que los conocemos con mayores precisiones, resultarían excesivamente discordantes en relación a 1841 con aranzadas de otras medidas.

Mapa 1. Área de influencia del monasterio de San Millán de la Cogolla en La Rioja, según el Catastro del Marqués de la Ensenada

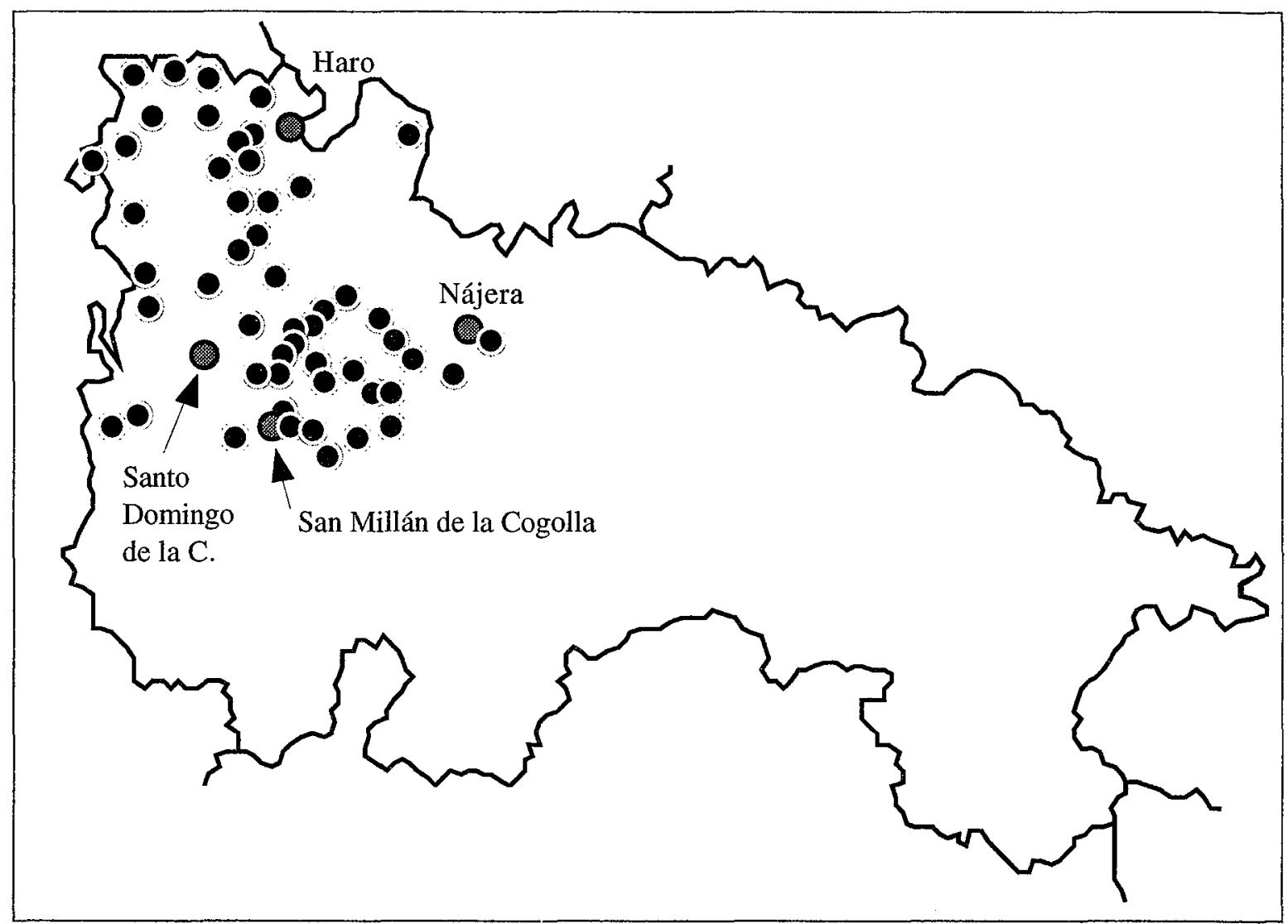

El resultado se puede observar en el Cuadro 2, donde se comparan los totales según la suma de medidas y según su conversión a hectáreas. El patrimonio rústico del monasterio de San Millán de la Cogolla se acercaba a las mil ochocientas hectáreas a mediados del siglo XVIII, cien años después sobrepasaba esa cifra. El monasterio disponía en ambas fechas, ante todo, de tierra de sembradura destinada al cereal, más en el dieciocho que en el diecinueve. Entre 1752 y 1841 la dimensión de la explotación agrícola del monasterio aumentó en más de 68 hectáreas. Este incremento fue generalizado en todos los tipos de tierra de cultivo. En números absolutos, creció notablemente la tierra destinada a la sembradura, con más de 75 hectáreas, y la tierra ocupada por el viñedo, 37 hectáreas. Por contra, los prados dejaron de tener interés para el cenobio, casi desaparecieron de su predio, sin que sepamos con seguridad si lo fue por venta o por su conversión en tierra blanca para el cereal. En fin, el monasterio de San Millán apostó por la agricultura despreciando la tierra destinada al man- 
tenimiento de la ganadería. Igualmente se debe observar que la vid, aún siendo modesta su presencia en el dominio del monasterio, adquirió mayor protagonismo (del $9,6 \%$ al $11,3 \%$ ) y realmente fue el cultivo que más se incremen tó entre 1752 y 1841 , más del $21 \%$, frente al $5 \%$ de la sembradura. La importancia que concedieron a la vid los administradores del monasterio queda patente en el hecho de que aún siendo tan destacado el aumento de su superficie como la importancia en el conjunto del predio, disminuyó el número de villas en las que se cultivaba: si en 1752 disponían de viñas en dieciocho lugares, en 1841 su número se reducía a diez (nueve antiguos más uno nuevo). La explotación de la vid siguió un proceso de concentración.

La importancia del monasterio de San Millán de la Cogolla en el área geográfica que se inscribe era notable, su dominio, sus derechos jurisdiccionales, su influencia cultural, la importancia de su botica, etc. eran palpables ${ }^{16}$, pero, contradictoriamente, todo ello se reducía al final de su historia a unas áreas geográficas muy concretas: el valle del Cárdenas, donde se levantaba el propio monasterio, el del río Tuerto, paralelo al primero, y los del río Oja y Tirón, más al noroeste. Podríamos pensar que sólo la propiedad de la tierra se reduce a esos valles, pero no, sus derechos jurisdiccionales, las iglesias anejas, los monopolios de producción (molinos, trujales, etc.), las exenciones decimales y el control espiritual, también se reducían a esos valles (ver Mapa 1). Todo el dominio gira entre el espacio que se controla desde el mismo cenobio al pie del monte San Lorenzo y desde la granja de Cihuri (ver Mapa 2). En uno y otro siglo la estructura agraria se mantiene, no se observan cambios sustanciales en la administración, tampoco políticas agrarias concretas. Desde 1752 hasta 1841 el terrazgo aumenta y decrece en los diferentes municipios sin un orden aparente, tan sólo se observa un proceso de concentración de la vid, ya descrito antes, y la preferencia por las administraciones más cercanas al cenobio, por lo demás no hay novedades destacables, al menos, desde la documentación manejada ${ }^{17}$.

Sabemos muy poco de la división social de la tierra en La Rioja, tanto a mediados del siglo XVIII como en los inicios del régimen liberal, pero intuímos que el dominio de San Millán era uno de los más extensos de la provincia. No podemos comparar el dominio del cenobio con los grandes propietarios laicos de la región, pero sí con el clero regular, al menos, para 1841.

Los resultados del Cuadro 2 son por sí mismos muy elocuentes. El dominio del monasterio benedictino de San Millán de la Cogolla no sólo es el más privilegiado económicamente del clero regular de toda la provincia de Logroño en

16. PEÑA, Fray J., Páginas emilianenses, Salamanca 1972.

17. Es posible que sí existan actuaciones concretas tendentes a la mejora de las diferentes administraciones locales pero convendrían ser estudiadas más detenidamente antes de pronunciarnos más taxativamente. En todo caso, ver SÁENZ RUIZ-OLALDE, J.L., San Millán de la Cogolla. Historia económica, administrativa y social en la época moderna, Pamplona 1992. 
1841, sino que lo es con una diferencia sustancial. Su patrimonio rústico supera a los del establecimiento más cercano de este mismo grupo eclesiástico, también sin duda de los mayores propietarios de la provincia, el monasterio, igualmente de benedictinos de Santa María la Real de Nájera, en nada menos que en unas seiscientas hectáreas. Esta diferencia tan notable, nos permite afirmar que también en el siglo XVIII, San Millán era el monasterio con mayor propiedad de tierra en esta provincia.

Así que la fama y el poder del monasterio emilianense, incluso en el último siglo de su existencia que hemos analizado, precisamente no uno de los más brillantes de su historia, no es gratuita. Está solidamente sustentada en una y otra fecha por un dominio territorial abundante en hectáreas. Lo que, como consecuencia inmediata, le reportaba unas rentas considerables, que en en 1841 se cifran en 3.179 fanegas y 10 celemines de trigo, 495 fanegas y 10 celemines de cebada y 14.732 reales en efectivo, a las que se añaden otros 20.801 reales y 69 fanegas y 3 celemines de trigo procedentes de rentas urbanas.

Mapa 2. El dominio rústico del monasterio de San Millán de la Cogolla en La Rioja (media de las posesiones de 1752 y de 1841)

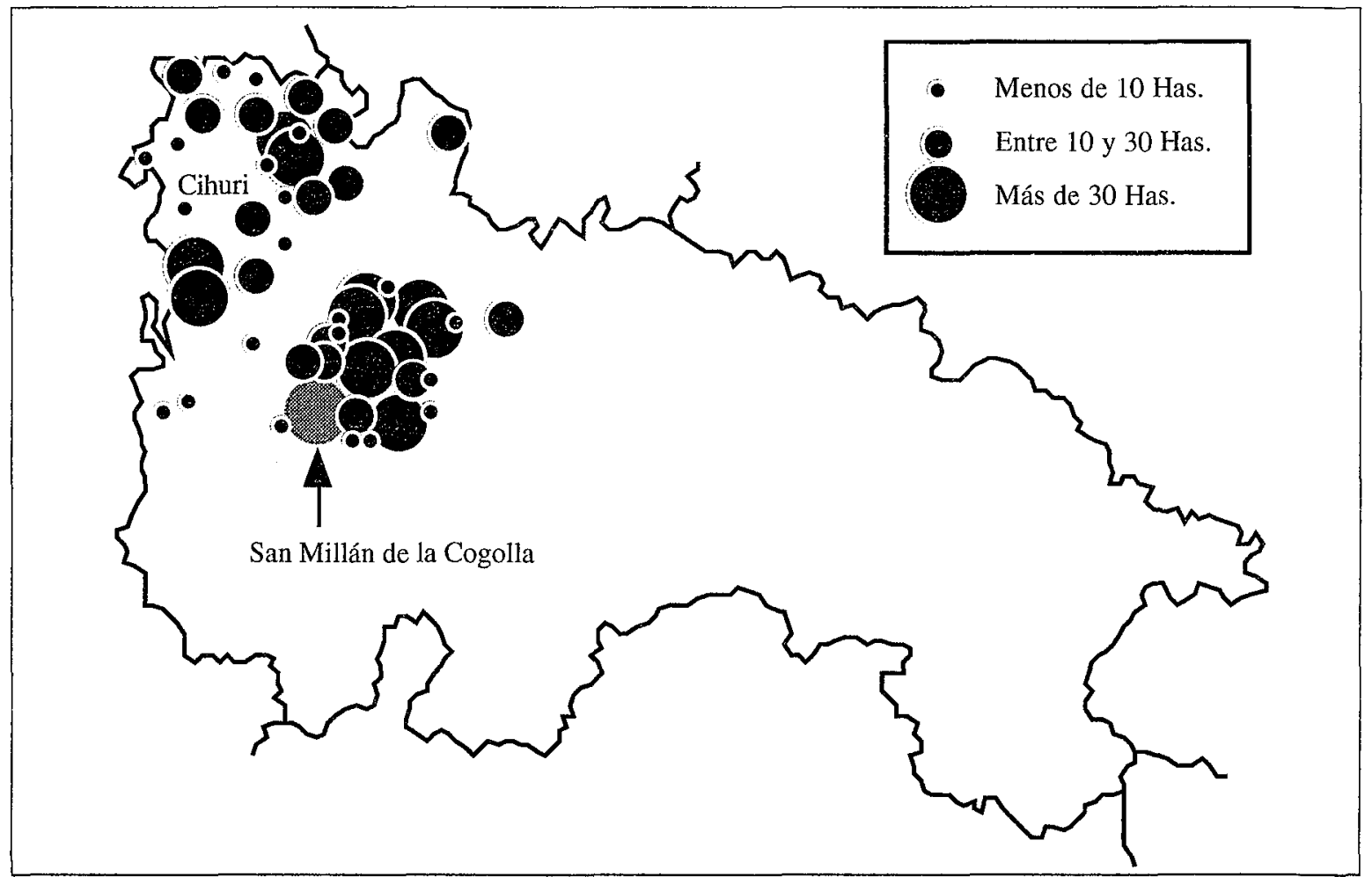

Hablemos a continuación de la distribución geográfica de la explotación agrícola del monasterio de San Millán de la Cogolla. La propiedad de la tierra del monasterio se distribuía por, al menos, cincuenta y cuatro entidades de población al final del Antiguo Régimen. Esta cifra aparenta una excesiva fragmentación geográfica de la explotación que un estudio más detallado desdice. Sólo la propiedad en tres municipios suponía más de la mitad del predio rústico del monasterio. La tenencia de tierra en los municipios que componían el 
Valle de San Millán ${ }^{18}$, la cercana villa de Badarán y Cihuri significaba para el monasterio concentrar más de mil hectáreas. En efecto estos tres municipios eran el centro de la explotación agrícola emilianense.

Cuadro 3. Los dominios rústicos de las ordenes religiosas en La Rioja en 1841

\begin{tabular}{|c|c|c|c|}
\hline Orden religiosa & Avecindada en & Has & $\%$ \\
\hline \multirow[t]{2}{*}{ Agustinas } & Logroño & 55,4 & 0,7 \\
\hline & Ágreda (So) & 9,2 & 0,1 \\
\hline Agustinos & Haro & 118,0 & 1,5 \\
\hline \multirow[t]{5}{*}{ Benitos } & San Millán de la Cogolla & $1.851,5$ & 23,6 \\
\hline & Santa María la Real, Nájera & $1.245,2$ & 15,9 \\
\hline & Valvanera (Anguiano) & 883,6 & 11,3 \\
\hline & El Espino (Valladolid) & 24,5 & 0,3 \\
\hline & Obarenes (B) & 2,3 & 0,0 \\
\hline \multirow[t]{3}{*}{ Bernardas } & Cañas & 319,2 & 4,1 \\
\hline & Herce & 125,6 & 1,6 \\
\hline & Santo Domingo de la Calzada & 194,3 & 2,5 \\
\hline \multirow[t]{3}{*}{ Bernardos } & San Prudencio & 415,0 & 5,3 \\
\hline & Bugedo (B) & 0,0 & 0,0 \\
\hline & Herrera (B) & 588,1 & 7,5 \\
\hline \multirow[t]{2}{*}{ Carmelitas descalzas } & Logroño & 67,4 & 0,9 \\
\hline & Calahorra & 82,1 & 1,0 \\
\hline \multirow[t]{2}{*}{ Carmelitas descalzos } & Calahorra & 0,4 & 0,0 \\
\hline & Logroño & 0,2 & 0,0 \\
\hline \multirow[t]{2}{*}{ Dominicas } & La Esperanza de Alfaro & 115,5 & 1,5 \\
\hline & Casalarreina & 153,6 & 2,0 \\
\hline \multirow[t]{2}{*}{ Dominicos } & Logroño & 53,8 & 0,7 \\
\hline & Vitoria & 78,8 & 1,0 \\
\hline \multirow[t]{5}{*}{ Franciscanas } & Entrena & 97,3 & 1,2 \\
\hline & Santa Elena, Nájera & 148,0 & 1,9 \\
\hline & Madre de Dios, Logroño & 158,3 & 2,0 \\
\hline & La Concepción, Alfaro & 89,8 & 1,1 \\
\hline & Santa Clara, Arnedo & 31,3 & 0,4 \\
\hline \multirow[t]{2}{*}{ Franciscanos } & Alfaro & 0,4 & 0,0 \\
\hline & Vico, Arnedo & 0,5 & 0,0 \\
\hline
\end{tabular}

18. El Valle de San Millán reunía las villas de Estollo, Berceo y la villa de San Millán con el lugar de El Rió, entidades que a efectos de jurisdicción territorial aparecen inseparables en las fuentes durante la Edad Moderna, lo que no significa que no dispusieran de términos o pagos específicamente propios. PEÑA, Fray J., "La villa de San Millán de la Cogolla», San Millán de la Cogolla en su XV centenario (473-1973), Logroño 1974, pp. 151-169. 


$\begin{array}{llrr} & \text { Calahorra } & 0,0 & 0,0 \\ & \text { Cornago } & 2,0 & 0,0 \\ & \text { Logroño } & 0,2 & 0,0 \\ & \text { Nájera } & 1,4 & 0,0 \\ & \text { Nalda } & 1,1 & 0,0 \\ & \text { Navarrete } & 0,5 & 0,0 \\ & \text { Santo Domingo de la Calzada } & 1,7 & 0,0 \\ & \text { Torrecilla de Cameros } & 30,1 & 0,4 \\ \text { Jerónimos } & \text { La Estrella, San Asensio } & 440,0 & 5,6 \\ \text { Mercedarios calzados } & \text { Lan Miguel del Monte, Miranda (B) } & 131,0 & 1,7 \\ \text { Trínitarios calzados } & \text { Alfaro } & 105,9 & 1,3 \\ & \text { Logroño } & 162,5 & 2,1 \\ & & 61,6 & 0,8\end{array}$

TOTAL

$7.847,3$

100,0

En Cihuri el monasterio de San Millán era el propietario de $97 \%$ de todo el municipio según las respuestas particulares del Catastro de Ensenada ${ }^{19}$, más de ochocientas hectáreas: labrantío, carrascales, alamedas, olivos, huertas... EI priorato era dirigido por fray Eugenio Muro, quien disponía de un criado ma yor de edad para la labranza ayudado de una yunta de bueyes, otro criado menor al servicio del monje y de dos criadas para la casa. Debía atender a 310 cabezas de ganado lanío y para acercarse al monasterio hacía uso de una mula de viajes. El cura de la villa de Cihuri era otro monje del cenobio, fray José Vírgala, ayudado en los oficios religiosos por un criado menor $y$, en casa, por una criada. La presencia del cenobio incluía también a fray Pedro Martínez, prior administrador de la ermita-santuario de Nuestra Señora de la Esclavitud, extramuros de Cihuri y propia del monasterio desde que antaño la trocó por la de Ternero al monasterio de Herrera. Fray Pedro, como los otros monjes, se servía de un criado mayor de edad para uso en la agricultura y de dos criadas que le atendían en las labores de su casa. Al monasterio no sólo le pertenecía la tierra, también las construcciones, que las daba en arriendo a los 35 vecinos (sin los frailes) que moraban en el lugar, unos 133 individuos. Cihuri era del señorío del monasterio de San Millán aunque la jurisdicción civil y criminal le correspondía a la cercana ciudad de Santo Domingo de la Calzada. El molino harinero, uno de los medios de producción de los que disponía el monasterio aquí y por otros lugares de su dominio, estaba situado sobre el Tirón y disponía de dos ruedas y de un pajar que arrendaba a los vecinos del lugar; los mismos vecinos también pagaban renta por el horno de cocer pan propio del monasterio. Por último, como señor espiritual el monasterio se llevaba el diezmo y la primicia,

19. AHPLo, Catastro de Ensenada, caja 192, libro 225. 
Mapa 3. Distribución por municipios de los cultivos en 1752 y 1841 del dominio rústico del monasterio de San Millán de la Cogolla

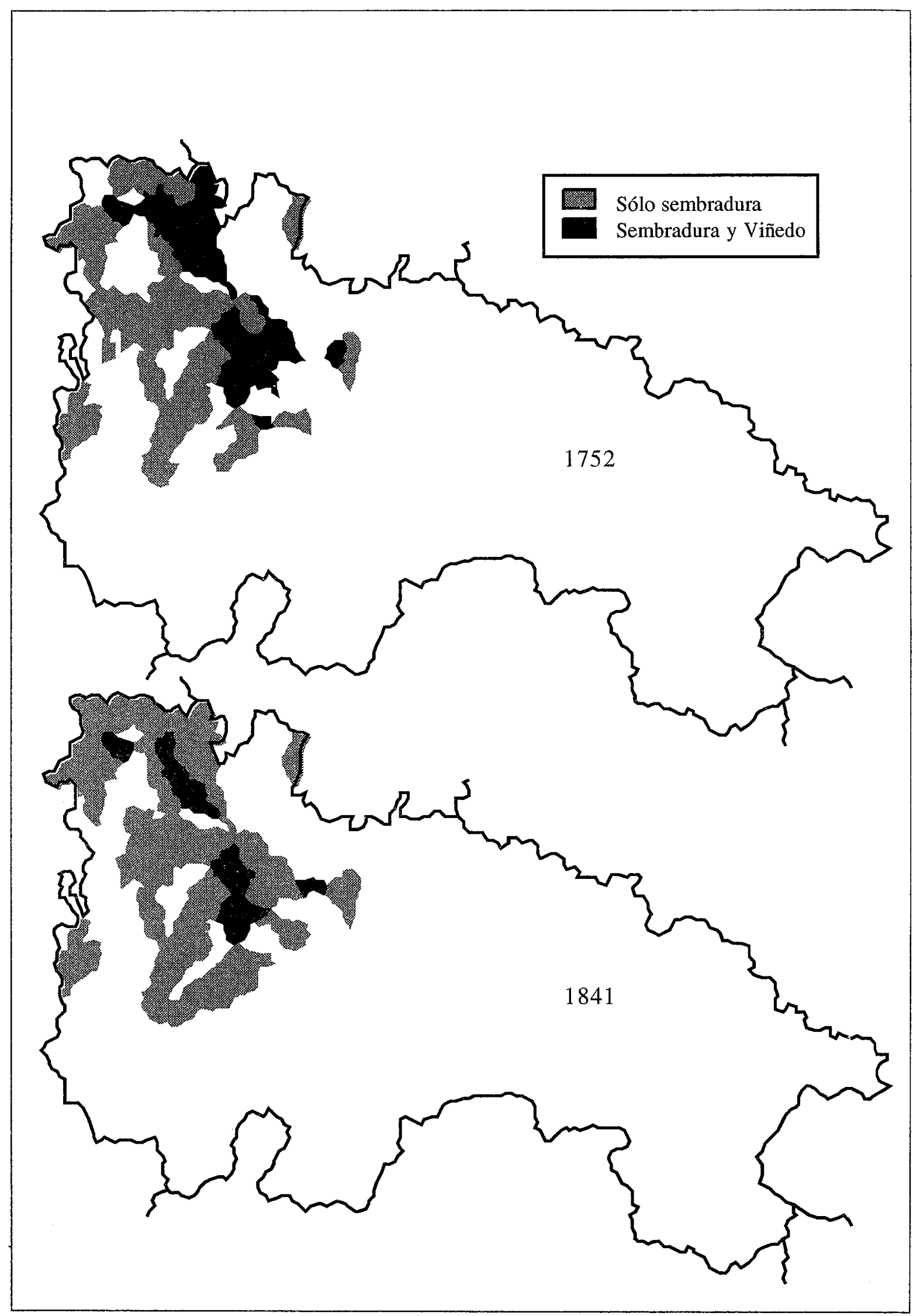


que en 1752 le reportaban, según los cálculos de los peritos catastrales, 3.980 reales.

Cuadro 4. La concentración del dominio rústico del monasterio de San Millán. Localización de las mayores haciendas

\begin{tabular}{lrrrrr}
\hline & 1752 Has & \multicolumn{1}{c}{$\%$} & 1841 & Has & $\%$ \\
\hline Valle de San Millán & 372,28 & 21,5 & 359,09 & 19,4 \\
Cihuri & 403,86 & 23,3 & 346,01 & 18,7 \\
Badarán & 238,35 & 13,8 & 265,19 & 14,4 \\
Cordovín & 73,11 & 4,2 & 122,54 & 6,6 \\
\hline TOTAL VILLAS & $1.087,60$ & 62,8 & $1.092,83$ & 59,2 \\
\hline
\end{tabular}

Sólo tierras de sembradura, huerta y viña. El \% es respecto al conjunto del dominio rústico (tierras cultivadas) del monasterio en La Rioja

Evidentemente Cihuri era el centro del monasterio de San Millán en el valle del Oja-Tirón, desde aquí se administraban los bienes del monasterio situados en las villas cercanas: las rentas, diezmos y tributos de Anguciana, Bañares, Castañares, Casalarreina, Cuzcurrita del río Tirón, Haro, Leiva, Negueruela, Rodezno, San Millán de Yécora, Tirgo, Treviana, Villalobar, Zarratón, Tormantos, Sajazarra y otros se enviaban a Cihuri. La propiedad rústica situada en el valle del Oja-Tirón, aunque creció desde mediados del XVIII hasta 1841, lo hizo en mucha menor medida que la dispuesta en el valle del Cárdenas y del río Tuerto. Efectivamente, allí la tierra labrantía no aumentó ni un 2\%, aquí sobrepasó el $10 \%{ }^{20}$. Al parecer existe una tendencia de sólo acrecentar el dominio en las villas situadas en el Cárdenas y sus áreas limítrofes, siguiendo el curso del río Najerilla, las más próximas al cenobio. Inmediatamente debemos relacionar esta predilección con el aumento de la tierra dedicada a la vid, porque en estos valles la demanda de vinos está forzando a la plantación de viñas en una tierra más proclive y en lugares mejor situadas comercialmente (pensando en el abastecimiento de la sierra de la Demanda) que las villas del OjaTirón inevitablemente en un segundo plano eclipsadas por la viticultura de la zona de Haro $^{21}$. El caso de la villa de Cordovín ejemplariza muy bien estas circunstancias. Cordovín se sitúa a escasas leguas de la casa de San Millán y además es limítrofe con unos de los grandes dominios del cenobio, Badarán. El monasterio emilianense disponía en Cordovín de la cuarta parte de la tierra cul-

20. Datos que contrastan con el interés que manifestaron algunos abades, como el padre Eugenio Muro (cesado en 1757), por atraer más población a Cihuri con la construcción de nuevas casas, lo que quizá, más bien, sea un indicativo de las dificultades que atravesaba la explotación agraria en esa zona más que un crecimiento de la misma.

21. IBÁÑEZ RODRÍGUEZ, S., "Especialización agraria en el Alto Ebro (La Rioja): la cultura del vino, 1500-1900», Brocar 20 (1996), pp. 211-235. 
tivable, de uno de los dos trujales de uva existentes en el pueblo, era el señor espiritual, recibía los derechos señoriales de castillería, martiniega y fumazgo (conocido localmente como polla de la botera) y gozaba los consabidos impuestos religiosos de diezmos y primicias aunque parte se los llevase el fraile puesto por el cenobio para los servicios religiosos. Aquí el monasterio poseía en 1752 un total de 73 hectáreas (el $41 \%$ de viña), en menos de cien años el dominio se incrementó un $67 \%$ y en 1841 de las 123 hectáreas el $57 \%$ era viña (un incremento del $130 \%$ ). Cuando el monasterio daba en arriendo las viñas procuraba contratos de larga duración, siendo los de ochenta años los más comunes, con ello se evitaba que se sobreexplotase la vid y que el rentero tendiese a la mejora del majuelo y que, en buena parte, se amortizasen las replantaciones ${ }^{22}$, pero no olvidemos que estos contratos largos eran comunes desde siglos pasados ${ }^{23}$.

El Valle de San Millán o, en conjunto, todo el valle del río Cárdenas, el contiguo hacia el norte del río Tuerto y el colindante al sur, el valle del RiocojaTobía, era en este siglo, como lo fue hasta entonces, toda una mancha de propiedad rústica del monasterio de San Millán de la Cogolla. Tan sólo en el propio Valle de San Millán, Badarán, Cárdenas y Cordovín el monasterio disponía de la cuarta parte de toda la tierra cultivada según el catastro de Ensenada y, por supuesto, era el propietario de la tierra de mejor calidad. Pero no sólo en estos municipios, algunos de ellos con una historia local únicamente comprensible por la existencia del monasterio, el dominio seguía hacia Villaverde, Bobadilla, Tobía, Matute, Ollora, Pazuengos, Villar de Torre, Villarejo, Cañas, Canillas, Alesanco, Azofra, Nájera, Alesón, Camprovín, etc. mezclando todo tipo de jurisdicciones civiles y espirituales, el control en exclusividad de los molinos harineros, el cobro de primicias y diezmos, con propiedades labrantías y de usos del monte, con ganado lanar y cabrío, con viña y cereal, con la huerta de Badarán o el coto redondo junto al monasterio, cobrando martiniegas, humazgo, recibiendo veredas y sernas, aunque al finalizar el Antiguo Régimen ya todo ello muy devaluado, etc.

La explotación agrícola del monasterio de San Millán se nos presenta muy parcelada. Aún donde el dominio rústico es muy importante, como en Badarán o en el Valle de San Millán, la parcelación es enorme. El dominio de San Millán en 1752 se componía de la agregación de casi dos mil doscientas parcelas de labrantío: 1.966 tierras dedicadas a sembradura, 383 de huertas y 174 de viñas. La explotación del monasterio se forma a mediados del siglo XVIII con parcelas medias de poco menos de una hectárea, 0,80 Has. En 1841 la parcelación es algo menor, aunque sigue por debajo de la hectárea, la unidad de explota-

22. RUIZ-OLALDE, J.L., San Millán de la Cogolla... pp. 320 y ss.

23. BRUMONT, F., «La rente de la terre en Rioja occidentale a l'epoque moderne», Melanges de la Casa de Velázquez 16 (1980), pp. 237-272. Del mismo, Campo y campesinos de Castilla la Vieja en Tiempos de Felipe II, Madrid 1984, pp. 16 y ss. 
ción es de 0,89 Has. La parcelación presenta variaciones significativas en función de los cultivos; en tiempo del Catastro es muy elevada en la huerta con parcelas de 0,11 Has. frente a las viñas, con parcelas de una hectárea. La viña es la que más variaciones manifiesta de un siglo a otro, en 1841 la parcela alcanza las 2,17 Has. frente a las 0,99 de 1752 . En conjunto, en uno y otro si glo más del noventa por ciento del terrazgo del monasterio se divide en parcelas inferiores a la hectárea y tan sólo el 3\% presenta parcelas superiores a las seis hectáreas. Las mayores parcelas las encontramos, como no podía ser menos, en el Valle de San Millán, Badarán y Cihuri.

El monasterio de San Millán de Cogolla ha gozado durante el último siglo de su existencia (1752-1841) de una privilegiada explotación agrícola cuantificada en unas dos mil hectáreas. Esta posesión le situaba en uno de los primeros puestos de la lista de los grandes propietarios de La Rioja. Este nivel económico es, sin duda, una de las causas fundamentales del destacadisimo peso que esta institución tenía en la región, evidentemente en lo religioso, pero también en lo cultural y social.

La estructura interna de la tenencia del dominio rústico de este centro monacal, plasmada en este trabajo, necesariamente tiene que potenciar aún más la influencia socio-económica-religiosa. Sus alrededor de dos mil doscientas parcelas distribuídas por algo más de medio centenar de términos municipales de casi toda la Rioja Alta hace que el control de los monjes, o del señorío de abadengo, sobre los habitantes, esté siempre muy próximo y presente. $Y$ en consecuencia no es sólo el tañido de las campanas, o los símbolos y poderes de signo estrictamente espiritual, los que regulan la vida de los campesinos y moradores de los pueblos, sino que también existen otros mecanismos coercitivos más poderosos e íntimamente ligados a la tierra. El cobro de las rentas en especie marca las estaciones del año, así como el de los diezmos y el de los alquileres de las fincas urbanas definen el ritmo de las anualidades.

La fragmentación interna del terrazgo, esté o no su origen en la génesis de la formación del dominio, alcanza, pues, una dimensión ulterior a la mera característica o rasgo definidor del paisaje agrario. La subdivisión de la propiedad en numerosas parcelas, medidas en un altísimo porcentaje en celemines $\mathrm{y} / \mathrm{o}$ en muy pocas fanegas, como hemos demostrado, tiene otras evidentes finalidades relacionadas íntimamente con el usufructo de la tierra, cuales son, entre otras, la de facilitar el control de la extracción de la renta, y la de vincular al monasterio con el mayor número posible de habitantes ampliando de este modo sus redes clientelares de dominación. En esta organización de las cesiones de la tierra están, sin duda, los verdaderos poderes del monasterio. Y, como vemos, se orienta evidentemente bajo una dirección de escaso signo aretalógico cris- 
tiano, pues se reducen, como asimismo es la norma del resto de los propietarios del sistema, a meros poderes terrenales.

Otro tanto se puede afirmar del uso de la tierra. La definición de un paisaje de clarísimo modelo cerealero, como hemos visto, no se guía por el óptimo aprovechamiento del terrazgo, sino por el marco de una economía rentista de signo marcadamente especulativo y escasamente monetarizada. La necesidad de mano de obra abundante y el riesgo subsiguiente a la transformación de su producto relega el cultivo de la viña y lo reduce a un espacio muy limitado, en favor del espacio dedicado al cultivo del cereal. $Y$ esto mismo sucede con los tipos de cobranza de la renta, con la localización y uso de las fincas urbanas, y con el monopolio ejercido en los medios de transformación de los productos agrarios.

Mencionaremos, por último, la permanencia del dominio rústico del monasterio de San Millán durante un siglo que se suponía de transformación del Antiguo Régimen. Las propiedades siguen siendo esencialmente las mismas y su estructura espacial idéntica. Ante estas circunstancias parece que únicamente decisiones políticas podrían doblegar un sistema. 